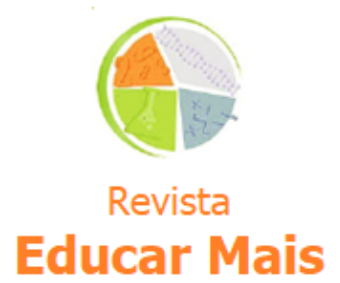

\title{
Concepções de um grupo de professores de ciências de escolas públicas de Pelotas/RS sobre ensino experimental
}

\section{Conceptions about experimental teaching of a group of science teachers from public schools in Pelotas / RS}

Gabriela Soares Traversi'; Vitor Hugo Borba Manzke; Rita Helena Moreira Seixas ${ }^{1}$; Valmir Heckler ${ }^{2}$

\section{RESUMO}

Neste trabalho discorremos sobre a investigação realizada no ambiente de escolas públicas localizadas no município de Pelotas/RS, em relação ao ensino experimental. Diversos pesquisadores têm desenvolvido pesquisas que tratam do ensino de ciências e a importância da experimentação neste contexto. Entretanto, em meio aos professores do ensino básico a experimentação parece estar aquém do potencial existente no ambiente escolar. Isso nos estimulou a conhecer o que professores deste nível de ensino, entendiam sobre o ensino experimental como estratégia didática para o estudo das ciências da natureza. Após vivenciarmos o ambiente investigado e levantados dados junto aos professores envolvidos no projeto vimos que existe espaço para ampliarmos as discussões sobre a importância da experimentação em sala de aula, visando romper com protocolos engessados, rígidos utilizados atualmente pelos professores. Para que se torne possível este novo ambiente é necessário que os professores ampliem seus conceitos sobre a experimentação e a diversificação das suas atividades, estimulando a criatividade de seus alunos.

Palavras-chave: Experimentação; Ensino de Ciências.

\begin{abstract}
In this work we discuss the investigation carried out in the environment of public schools located in the city of Pelotas / RS, in relation to experimental teaching. Several researchers have developed research that deals with science teaching and the importance of experimentation in this context. However, among elementary school teachers, experimentation seems to be below the potential in the school environment. This stimulated us to know what teachers at this level of education understood about experimental teaching as a didactic strategy for the study of the natural sciences. After experiencing the environment investigated and collected data from the teachers involved in the project we saw that there is room to broaden the discussions about the importance of experimentation in the classroom, aiming to break with the plaster, rigid protocols currently used by teachers. To make this new environment possible, teachers need to broaden their concepts about experimentation and diversification of their activities, stimulating the creativity of their students.
\end{abstract}

Keywords: Experimentation, Science Teaching.

\footnotetext{
${ }^{1}$ IFSul - Instituto Federal de Educação, Ciência e Tecnologia do Sul-rio-grandense, Pelotas/RS - Brasil.

2 FURG - Universidade Federal do Rio Grande, Rio Grande/RS - Brasil.
} 


\section{INTRODUÇÃO}

O ensino experimental é foco de debate e de reflexão na educação em Ciências, além de ter papel importante nos programas de ciências das escolas em muitos países. Professores e gestores de currículo compartilham a crença nas potencialidades da experimentação como metodologia de ensino (GALIAZZI et al, 2001; MATOS; MORAIS, 2004).

Um dos princípios do ensino deve ser a liberdade de aprender, ensinar, pesquisar e divulgar a cultura, o pensamento, a arte e o saber. Nesse sentido, a experimentação é vista como uma das fontes de busca de informações variadas, permitindo ao estudante uma elaboração ou reelaboração de suas atitudes e ideias, desenvolvendo uma maior autonomia no processo de obtenção de conhecimento (BRASIL, 1998; BRASIL, 2014).

De acordo com os PCN's (BRASIL,1998), não se deve confundir a experimentação com um conjunto de objetivos e métodos de ensino. Assim, as atividades não podem se limitar a nomeações e manipulações de vidrarias e reagentes fora do contexto experimental. Tais atividades deverão garantir o espaço para a reflexão, o desenvolvimento e a construção de ideias, conhecimentos, procedimentos e atitudes.

A introdução de atividades experimentais nas aulas de Ciências, tanto no Ensino Fundamental quanto no Ensino Médio, não resolve as dificuldades de aprendizagem dos estudantes se o conhecimento científico e suas observações, vivências e medições forem tratados pelos professores como fatos que devem ser memorizados. Tais dificuldades poderão ser vencidas se as aulas em que o professor utiliza o ensino experimental forem tratadas como eventos que requerem investigação, explicação e discussão geradas pelos alunos e mediadas pelos professores (BORGES, 2002).

Contudo, em grande parte dos casos, o experimento é trabalhado como uma atividade de demonstração, em que o professor utiliza um protocolo ou guia de experimento para explicar determinado fenômeno. Nesse caso, a participação dos estudantes consiste em observar e acompanhar os resultados, porém, esta participação pode ser melhorada se o professor solicitar que os alunos apresentem suas expectativas em relação aos resultados, expliquem aqueles que foram obtidos e comparem com os esperados (BRASIL, 1998).

Os profissionais que se valem de métodos científicos que engessam as ideias e descartam os erros, trazendo receitas prontas, impedindo que o indivíduo pense, formule suas próprias hipóteses e exponha seu ponto de vista sobre determinado tema guiam-se por regras ingênuas que nem sempre explicam o labirinto de interações que pode ocorrer ao longo da história e da existência humana (FEYERABEND, 2011).

Sendo assim, durante a experimentação, é essencial que se proponha a problematização para que os estudantes sejam guiados em suas observações. Quando o professor ouve os alunos, passa a conhecer suas interpretações e instiga-os a olhar de outro modo para o objeto em estudo (BRASIL, 1998).

Porém, muitos professores ainda possuem compreensão equivocada do verdadeiro sentido da experimentação para as aulas de Ciências. É preciso superar a ideia de que a experimentação só pode ser desenvolvida em locais como os laboratórios didáticos, utilizando equipamentos e métodos prontos. Nesse sentido, a compreensão da utilização de diferentes artefatos científicos em atividades 
pedagógicas para além do laboratório se constitui em um desafio para a formação de professores de ciências (HECKLER, 2014).

O contato com o ensino experimental durante a graduação contribui para o aperfeiçoamento da prática no momento em que permite ao graduando visualizar os conteúdos teóricos, porém, é importante que a didática dessas atividades seja explorada para que a experimentação não seja vista apenas como ilustração da teoria ou como uma maneira de colocar em prática determinada técnica, sempre vinculado a um laboratório com equipamentos de última geração (TRAVERSI, 2016).

Segundo Gioppo et al (1998), a formação do professor e a desconstrução da ideia de que só se faz experimentação no laboratório são pontos fundamentais para o reconhecimento dos principais problemas que afetam o papel das atividades experimentais.

Baseando-se nestas ideias, o presente estudo buscou responder à seguinte questão de pesquisa: quais são as concepções dos professores de Ciências de escolas públicas de Pelotas sobre Ensino Experimental?

Sendo assim, buscamos entender que concepções os professores de Ciências de escolas públicas de Pelotas têm sobre Ensino Experimental. Isto porque em outros estudos que desenvolvemos e ouvindo os professores deste nível de ensino, nos cursos de formação continuada que temos oferecido através do Programa Núcleo de Estudos em Ciências e Matemática (PRONECIM), vimos a necessidade de conhecermos as concepções trazidas por estes professores de maneira que nos permitisse compreender o que efetivamente pensam sobre o ensino experimental.

A intenção passou a ser a de conhecer e caracterizar os professores de forma que pudéssemos classificar as atividades experimentais desenvolvidas quanto as metodologias utilizadas e as estratégias didáticas que fossem identificadas. Entendíamos que através do conhecimento gerado sobre as estas atividades experimentais, poderíamos obter um conhecimento mais aproximado das concepções trazidas por estes professores na sua formação inicial ou no desenvolvimento de suas ações em sala de aula.

\section{DESENVOLVENDO O ESTUDO}

Para conhecer os fatos advindos da proposta de trabalho tomamos como fundamento a pesquisa qualitativa, pois ela permite construções entre a realidade, a própria pesquisa e o campo ou as pessoas que estuda, considerando a existência de uma relação dinâmica entre mundo real e sujeito, trabalha com valores, crenças, opiniões, atitudes e representações. Dessa forma, é possível conceituar o modo como os sujeitos da pesquisa relacionam-se com o contexto estudado a partir de suas experiências, ações e interações (FLICK, 2004; MINAYO, 2007).

A pesquisa ocorreu entre os meses de abril e junho do ano de 2016, tendo como participantes os professores egressos dos cursos de Licenciatura na área de Ciências, formados após o ano de 1998, pois a partir deste ano entram em vigor as resoluções da LDB (BRASIL, 2014) e dos PCN's (BRASIL, 1998), no que diz respeito às atividades experimentais em aulas de Ciências. 
Tais professores, no período em que a pesquisa foi realizada, atuavam em escolas municipais e estaduais da rede pública de ensino na zona urbana de Pelotas - RS ministrando a disciplina de Ciências nos anos finais do Ensino Fundamental.

Os dados foram coletados por meio de entrevista individual, previamente marcada com cada professor, semiestruturada e realizada na escola. Para registro das falas, foi utilizado um gravador Olympus VN - 8100PC. Após sua realização, cada entrevista foi transcrita utilizando o programa computacional Express Scribe Transcripition.

Para a análise dos conteúdos das entrevistas foi utilizando como metodologia a Análise Textual Descritiva (ATD), que tem como limites a análise de conteúdos e a análise de discursos. A finalidade dessa análise é produzir novas compreensões sobre discursos e fenômenos (MORAES; GALIAZZI, 2011).

A partir da ATD novas estruturas de compreensão acerca do assunto estudado foram construídas e expressas em produção escrita relacionando - se com as concepções dos pesquisadores, pressupostos deste estudo e referencial teórico escolhido.

\section{AMBIENTE DA PESQUISA}

O município de Pelotas possui trinta e nove escolas urbanas com Ensino Fundamental completo, (dados da Secretaria Municipal de Educação e $5^{a}$ Coordenadoria de Educação). Dessas, vinte e oito (quinze municipais e treze estaduais) participaram efetivamente da pesquisa. Das onze escolas restantes, duas estavam sem professor de ciências por motivo de licença, uma não quis participar do estudo e em três não foi possível o contato com os professores devido ao período de férias.

Das vinte e oito escolas participantes, cada uma tinha, no mínimo, um, e, no máximo, quatro professores de ciências atuantes nos anos finais do Ensino Fundamental, totalizando sessenta e quatro professores.

Após o contato prévio com as escolas, foram selecionados vinte e três professores que se enquadraram no critério previamente estabelecido de serem formados a partir do ano de 1998, destes, dezessete foram entrevistados. Dos seis professores que não foram entrevistados, um não quis dar entrevista, três estão afastados da escola por licença de saúde e dois não residem nem trabalham mais no município de Pelotas.

Os resultados serão apresentados em dois momentos: primeiro a caracterização dos professores participantes do estudo e, no segundo momento, as concepções dos professores sobre ensino experimental, resultantes da análise do conteúdo das entrevistas.

Estas concepções trazem a visão dos professores sobre o ensino experimental, classificação como metodologia ou estratégia didática, tipos de atividades adequadas ao termo e atividades experimentais que são realizadas. 


\section{CONHECENDO OS PROFESSORES E AS SUAS CONSEPÇÕES}

Os dezessete participantes da pesquisa foram identificados pela letra " $\mathrm{P}$ " seguida do número relativo à ordem em que as entrevistas foram realizadas, com a finalidade de garantir o anonimato dos professores. As informações sobre as horas trabalhadas referem-se à atuação em sala de aula mais as horas destinadas à preparação de aulas, chamadas de hora - atividade.

A idade dos professores variou de 26 a 49 anos, houve predominância do sexo feminino e o tempo de experiência em sala de aula de ensino de ciências foi de 1 a 15 anos. Quanto à qualificação profissional, cinco professores são graduados, cinco são especialistas, quatro são Mestres e três são Doutores. Em relação às horas em sala de aula, observou-se variação entre 20 e 60 horas semanais.

Os professores classificaram o ensino experimental como metodologia ou estratégia didática, elencaram as atividades que consideraram adequadas ao termo e citaram as atividades que são realizadas em sua prática docente.

As metodologias são meios para se chegar aos objetivos traçados no ensino, determinados pela relação objetivo - conteúdo. Agregam às atividades realizadas pelo professor e pelos alunos. Nesse sentido, o professor deve considerar a realidade escolar e as relações entre fatos e problemas que determinado conteúdo trás e, assim, traçar um planejamento coerente com objetivos claros e atividades que o permitam atingi-los (LIBÂNEO, 2013).

De acordo com Borges e Lima (2007), existem estratégias didáticas que promovem o diálogo entre teoria e prática e comportam que aos alunos sejam protagonistas da sua aprendizagem. Nesse sentido, o ensino experimental pode ser inserido nesse conceito.

Os autores acima elencam algumas estratégias como atividades práticas (construção de modelos, coleções escolares, atividades práticas diversas), jogos em sala de aula, atividades extraclasse (clubes de Ciências, campanhas na comunidade escolar, eventos, foto/construção de vídeos, palestras/filmes, trilha/saída de campo/estudo do meio, exposições/museus, horta, hidroponia, construção de banco virtual, reciclagem).

Alguns professores $(P)$ compartilham destes conceitos e consideram que o ensino experimental se encaixa em ambos, dependendo de sua aplicação, confirmando suas potencialidades:

"Se eu quero fazer um projeto com os alunos e adoto a metodologia desse projeto como um experimento, parte experimental, ele se torna uma metodologia, mas no momento em que eu monto meu plano de ensino, plano de estudo e uso as experiências dentro desse meu plano de estudo ele é uma estratégia didática". (P2)

"É uma metodologia de ensino porque é um método para ensinar e acho que é uma estratégia, pelo menos a ideia é facilitar o aprendizado de alguma forma, mostrando, na prática, aquela teoria que a gente fala..." (P6)

"Tem um pouco de cada coisa, porque não deixa de ser uma estratégia, uma forma de aproximação da teoria, mas também tem seu lado de metodologia porque a gente acaba tendo que traçar passos e fazer um desenvolvimento para que aquilo dê certo". (P16) 
Nos depoimentos acima, todos os professores entrevistados têm a ideia de que a experimentação ilustra a teoria de forma prática e que isso pode acontecer de diversas maneiras, ou seja, utilizando metodologias diferentes. Tais concepções ficam evidentes abaixo:

"... algo prático, ou seja, em que o aluno literalmente coloque a mão na massa, que não fique só na teoria, que não haja só os conceitos, mas a prática desses conceitos". (P2)

"... complementa, na prática, o que estamos trabalhando na teoria..." (P5)

"Para eles poderem ver na realidade aquelas características que estou falando, para eles poderem enxergar..." (P6)

"...experimentação é tu mostrares, em termos práticos, aquilo que tu estás trabalhando..." (P10)

Nesse sentido, o ensino experimental abrange diversas atividades que podem ser realizadas em diferentes lugares dentro ou fora da sala de aula e até da escola. Porém, o que todas essas atividades devem ter em comum é a utilização da investigação, fazendo com que o aluno tenha oportunidade de, ao se deparar com determinado assunto, elaborar as suas próprias hipóteses e, a partir delas, chegar aos seus próprios resultados e conclusões.

O professor, por sua vez, deve se valer dessas atividades de maneira que possa explorar a individualidade dos seus alunos e a sua própria, pois, ao se desprender de protocolos e métodos préestabelecidos, consegue estimular os estudantes a pensar e também trabalhar com seus erros e acertos.

Manzke (2000) afirma que a individualidade do professor não é valorizada no momento em que se prende a técnicas e métodos engessados, tornando-se um especialista na aplicação de manuais e a ação dos alunos restringe-se apenas à reação de estímulos para respostas já esperadas pela escola.

Já para Saviani (2012), o ensino tradicional é centrado no professor, aquele que detém o conhecimento e o transmite de forma sistematizada e linear, de acordo com os protocolos estabelecidos por outras pessoas.

Segundo Feyerabend (2011), todas as metodologias são limitadas por mais óbvias que sejam e as regras não são violadas por acidentes, falta de conhecimento ou desatenção: essa ruptura é necessária para o progresso da pesquisa, mesmo que as regras sejam baseadas e fundamentadas na epistemologia. Os métodos científicos engessam as ideias e descartam os erros, trazendo receitas prontas, impedindo que o indivíduo pense, formule suas próprias hipóteses e exponha seu ponto de vista sobre determinado tema.

A imposição de regras imutáveis e estritas, para Moreira (2009), deixa a ciência mais objetiva, uniforme e tediosa, o que remete à educação científica de hoje, que simplifica a ciência bem como os sujeitos, deixando-a pouco humanizada.

Utilizar a experimentação, tanto como metodologia quanto como estratégia didática, permite ao professor centralizar a construção do conhecimento no aluno, dando a ele o protagonismo de sua aprendizagem. De acordo com Saviani (2012), metodologias novas estão centradas nas motivações e interesses do estudante por meio do desenvolvimento de procedimentos que permitam aos alunos a posse de seus conhecimentos. 
Ao ser questionada sobre as atividades que se inserem no termo ensino experimental, a maioria dos professores elencou atividades experimentais em laboratório e aulas práticas em ambientes externos. A utilização de diferentes recursos também foi citada por alguns professores, como o uso de jogos, documentários, informática, livros ou revistas.

"Eu acho que, além das práticas convencionais, estou usando bastante com os alunos o uso de jogos lúdicos, atividades com tecnologias e informática e acho que ali eles estão experimentando, eu uso simuladores na informática, acho que isso é bastante importante". (P5)

"...eu sempre tento levar para sala de aula exemplos, informações de revistas, utilizo vídeos também, pois acho que é uma forma deles visualizarem". (P11)

Outras práticas também foram apontadas, no entanto, as atividades de laboratório são as mais realizadas pelos professores deste estudo, seguidas das saídas de campo para coleta de material ou observações no próprio ambiente. Alguns professores, como P10 e P15, realizam diversas atividades, porém sempre no laboratório:

"...mas o que dá eu levo para o laboratório, corpo humano, tudo o que eu posso mostrar para eles, eu mostro no laboratório". (P10)

"Na parte de plantas, pteridófitas, trouxe eles para o laboratório e nós plantamos os soros da samambaia para ver o protalo, estrutura em forma de coração, foi bem legal. Com o 70 ano, estamos vendo animais, então, aqui no laboratório, tem alguns modelos anatômicos (...) geralmente eu trago para o laboratório, até porque eles adoram, eles pedem para vir". (P15)

A ideia de realizar atividades práticas diferentes das convencionais aparece nos depoimentos de $\mathrm{P} 1$, P13 e P16, que tentam fazer com que seus alunos visualizem o conteúdo teórico por meio da construção de histórias em quadrinhos, seminários, extração de tinta a partir de flores e frutas:

"...projeto com os pequenos de extrair tintas de frutas ou plantas, coisas que eles pudessem experenciar, no sentido de perceber, de interagir, não do experimento em si..." (P1)

"...conteúdo de física e química, separação de materiais, pedia que os alunos fizessem grupos e apresentassem na forma de seminário aí o pessoal se motivava bastante". (P13)

"...até uma história em quadrinhos, qualquer coisa pode ser, desde que a gente tenha a metodologia pra traçar como um experimento". (P16)

Em contrapartida, P4, P8 e P11, não levam seus alunos para o laboratório, e justificam que os alunos estão desmotivados:

"Muito difícil, porque eu fico com receio..." (P4)

"...eu já fiz bastante aula prática com eles há alguns anos atrás (...) uma coisa que a gente nota é o interesse deles; alguns anos atrás tu conseguias trabalhar, hoje em dia, está uma coisa muito difícil". (P8) 
"...eu não sinto eles motivados pras (sic) coisas, eu até tenho vontade de algumas coisas, mas como são tantos alunos às vezes eu me perco, no primeiro ano eu fui pro laboratório umas duas ou três vezes com turmas e foi um desastre..." (P11)

No entanto, P4 e P11 realizam outras atividades que consideram experimentais que acreditam serem bem aproveitadas pelos alunos, como a construção de maquetes, entrevistas e pesquisas em livros e revistas:

"Uma coisa que eu acho legal é a construção de maquetes, ajuda a visualizar (...) Entrevistas, por exemplo, para que eles conheçam o bairro onde vivem (...) eles têm dificuldades com o vocabulário, de entender as palavras do português, então eu dou uns textos para trabalhar o vocabulário". (P4)

"...eu sempre tento levar para sala de aula exemplos, informações de revistas, utilizo vídeos também, pois acho que é uma forma deles visualizarem (...) se eles vão montar uma maquete, por exemplo, é uma forma de estarem pesquisando, é uma forma de instigar a curiosidade deles em saber como é..." (P11)

Já P8 não realiza nenhum tipo de atividade experimental, apesar de ter as mesmas concepções que os demais, justifica sua posição de não realizar a atividade experimental pela falta de recursos e a desmotivação dos alunos:

"Acredito que a prática aliada à realidade deles, que é o que eu não venho conseguindo trabalhar, trazer mais assim para realidade deles (...) Os fungos até que dá para trabalhar bem, mas bactérias mesmo, células não tenho recursos (...) eles não têm a capacidade de aliar a teoria com a prática". (P8)

Ao analisar os depoimentos acima, foi possível perceber que os professores entrevistados acreditam nas potencialidades do ensino experimental tanto como metodologia quanto como estratégia didática, pois justificam que é uma prática necessária para que os alunos consigam visualizar os conteúdos trabalhados e, assim, chegar à aprendizagem. Essa constatação vai ao encontro dos PCN's, que afirmam que a experimentação é uma forma de dar autonomia aos alunos quando realizam por si mesmos as ações relacionadas à prática, no entanto, só conseguem a autonomia se forem guiados pelo professor (BRASIL, 1998).

Foi possível constatar que a maioria dos entrevistados vincula muito o ensino experimental com as atividades de laboratório e saídas de campo, tendo uma visão restrita no que diz respeito à diversidade de atividades que podem ser utilizadas em suas aulas para atingir a aprendizagem. Com isso, acabam por restringir a autonomia que poderia ser alcançada pelos alunos ao utilizar a experimentação.

Nesse sentido, Mata et al (2004) apontam que o significado de ensino experimental não é claro para muitas pessoas e, em certos casos, inspiram medo, pois estão associadas a teorias abstratas, conceitos difíceis, máquinas e equipamentos complexos. Esse medo precisa ser desmitificado e os professores devem ampliar suas concepções.

Confundir atividades práticas com a necessidade de um ambiente com equipamentos especiais para a realização de trabalhos experimentais é um erro cometido frequentemente, pois esses trabalhos podem ser desenvolvidos em qualquer sala de aula, sem a necessidade de instrumentos ou aparelhos sofisticados. Atividades diferentes como resolução de problemas, modelos, representações, desenhos, 
uso de mídias como computador, entre outras, mobilizam e envolvem os alunos e, muitas vezes, se sobressaem às atividades no laboratório, uma vez que não precisam de manipulação, repetição, ou seja, não necessitam dos velhos protocolos e regras, muitas vezes, aplicadas nesse ambiente (BORGES, 2002).

Considerando estes fatos, concluímos que os professores devem ampliar seus conceitos sobre ensino experimental e diversificar suas atividades, indo além do laboratório, explorando sua criatividade e estimulando a de seus alunos.

\section{CONSIDERAÇÕES FINAIS}

O ensino experimental não é a solução para os problemas de aprendizagem na disciplina de ciências, no entanto suas potencialidades como ação que auxilia na busca desta aprendizagem são conhecidas e compartilhadas pelos profissionais da área. A crença nessas potencialidades e a utilização da experimentação na prática pedagógica são influenciadas pelas vivências da formação inicial dos professores.

O presente estudo concluiu que a maioria dos professores pesquisados consegue realizar algum tipo de atividade experimental e muitos de uma maneira diversificada e adaptada ao contexto em que estão inseridos.

Mesmo que ainda existam professores que relacionam o ensino experimental a um laboratório com equipamentos caros e acabam vinculando a não utilização desta ferramenta à falta desses, os resultados mostram que a maioria dos professores participantes diversifica suas aulas experimentais, testando diferentes métodos, materiais e ambientes, adaptando-se ao contexto escolar e levando em consideração a capacidade individual de aprendizagem de seus alunos.

No que diz respeito à experimentação, a busca pela diversificação dos métodos faz com que o professor mostre sua face criativa e explore sua individualidade e, dessa forma, dá voz aos seus alunos, fazendo com que também desenvolvam sua individualidade e seu espírito criativo.

Nesse sentido, o professor contribui de forma significativa para a formação de um cidadão crítico, capaz de expor e defender seus pontos de vistas.

Diante disso, este grupo de professores acredita que essas atividades trazem muitas contribuições para o processo de ensino/aprendizagem. Além disso, mostra que as fragilidades existem, porém tais questões não devem ser uma barreira intransponível e, sim, mais um obstáculo a ser vencido na busca pelo ensino de qualidade.

Portanto, entendemos que existe necessidade de ampliarmos os conceitos sobre experimentação, romper com protocolos e métodos engessados, diversificando cada vez mais essa ferramenta, transformando-a em uma estratégia didática que contribua para a boa qualidade das aulas de ciências. 


\section{REFERÊNCIAS}

BORGES, Tarciso. Novos rumos para o laboratório escolar de Ciências. Cad. Brás. Ens. Fís., Belo Horizonte, v. 19, n. 3, p.291-313, dez. 2002.

BORGES, Regina Maria Rabello; LIMA, Valderez Marina do Rosário. Tendências contemporâneas do ensino de biologia do Brasil. Revista Electrónica de Enseñanza de las Ciencias, v. 6, n.1, p. 165-175, 2007.

BRASIL. Lei no 9.394, de 20 de dezembro de 1996. Lei de Diretrizes e Bases da Educação Nacional. 9. ed. Brasília, DF: Câmara dos Deputados, 2 maio. n. 118, 2014.

BRASIL. Parâmetros Curriculares Nacionais: Ciências Naturais. 1. ed. Brasília, DF: Mec/sef, 1998. FEYERBEND, Paul. Contra o método. 2. ed. São Paulo: Unesp, 2011.

FLICK, Ulrick. Uma introdução à pesquisa qualitativa. 2.ed. Porto Alegre: Bookman, 2004.

GALIAZZI, Maria do Carmo.; ROCHA, Jusseli Maria de Barros; SCHMITZ, Luiz Carlos; SOUZA, Moacir Langoni; GIESTA, Sérgio; GONÇALVES, Fábio Peres. Objetivos das atividades experimentais no Ensino Médio: A pesquisa coletiva como modo de formação de professores de Ciências. Ciência \& Educação, Bauru, v. 7, n. 2, p.249-263, 2001.

GIOPPO, Christiane.; SCHEFFER, Elizabeth Weinhardt; NEVES, Marcos C. Danhoni. O ensino experimental na escola fundamental: uma reflexão de caso no Paraná. Educar. UFPR, n.4, p. 39 57, 1998.

HECKLER, Valmir. Experimentação em Ciências na EAD: indagação online com os professores em AVA. Rio Grande: FURG, 2014. Tese Programa de Pós-Graduação em Educação em Ciências: Química da Vida e Saúde, Universidade Federal do Rio Grande, 2014.

LIBÂNEO, José Carlos. Didática. 2. ed. São Paulo: Cortez, 2013.

MANZKE, Vitor Hugo Borba. A Genética e seus temas embasadores (no ensino médio). Pelotas: Ed. Universitária Ufpel, 2000.

MATA, Paulina; BETTENCOURT, Conceição; LINO, Maria José; PAIVA, Marília Sousa. Cientistas de palmo e meio, uma brincadeira muito séria. Análise psicológica. v.1, n. XXII, p. 169 - 174, 2004.

MATOS, Margarida.; MORAIS, Ana Maria. Trabalho experimental na aula de Ciências Físico-Químicas do 30 ciclo do Ensino Básico: teorias e práticas dos professores. Revista de Educação, Lisboa, v. 12, n. 2, p.75-93, 2004.

MINAYO, Maria Cecília de Souza. $\mathbf{O}$ desafio do conhecimento: pesquisa qualitativa em saúde. 8. ed. Rio de Janeiro: Hucitec Abrasco, 2007.

MORAES, Roque; GALIAZZI, Maria do Carmo. Análise Textual Discursiva. 2.ed. Ijuí: Unijuí, 2011. 